\title{
Downscaling of GCM scenarios to assess precipitation changes in the little rainy season (March-June) in Cameroon
}

\author{
Edouard K. Penlap ${ }^{1,2, *}$, Christoph Matulla ${ }^{1,3}$, Hans von Storch ${ }^{1}$, \\ F. Mkankam Kamga ${ }^{2}$ \\ ${ }^{1}$ Institute for Coastal Research, GKSS Research Centre, Max-Planck-Straße, 21502 Geesthacht, Germany \\ ${ }^{2}$ Atmospheric Sciences Lab, Dept of Physics, Faculty of Sciences, University of Yaoundé I, PO Box 812, Yaoundé, Cameroon \\ ${ }^{3}$ Institute of Meteorology, University of Natural Resources and Applied Life Sciences, 1180 Vienna, Austria
}

\begin{abstract}
Large-scale climate forcings on local precipitation in Cameroon are analysed during the little rainy season (March-June). Variables found to have strong influence are used to downscale GCM projected rainfall for 2010-2049. In particular, 2 IPCC IS92a scenarios, simulated by the ECHAM4/OPYC3 climate model, are investigated. First, monthly precipitation data from 1951-1990 at 33 meteorological stations are grouped into homogeneous rainfall regions using self-organising feature maps (SOFMs). SOFMs identified 3 groups of stations with related time-series variability. Then, an empirical orthogonal function procedure, followed by canonical correlation analysis (CCA), is used to derive statistical relationships between the homogeneous regions and large-scale variables from the NCEP/NCAR Reanalysis Project. A CCA model is established for every region. Numerous fields at different pressure levels are used as macro-scale predictors. All possible combinations of 2 predictors are systematically tested in 3 validation experiments. Those combinations that perform well in the experiments are used to derive local-scale precipitation scenarios from the general circulation model (GCM) climate projection experiments. Different combinations of large-scale variables enter the model depending on region. A composite analysis suggests that precipitation is related to an advective (convective) phenomenon in the northern (southern) part of the study domain. Moreover, precipitation changes based on 2 IS92a emission scenarios as simulated by ECHAM4/OPYC3 are calculated. The trace-gas-only and the trace-gas-plus-sulphate integrations induce changes ranging locally from +44 to $-10 \%$ and from +36 to $-9 \%$ respectively, relative to the $1951-1990$ control period.
\end{abstract}

KEY WORDS: Cameroon $\cdot$ Precipitation $\cdot$ Regionalisation $\cdot$ Downscaling $\cdot$ Climate change

\section{INTRODUCTION}

Repeated drought and famine on the African continent in the last few decades have led to a high awareness of the effect of climate variability and the potential danger of future climate change (Hulme 1992, Nicholson 1993). The north of Cameroon, being in the Sahelian zone, has been affected, and the negative effects have been felt across the entire country, with some shortages in agricultural produce. Because agriculture in the country is entirely rain-fed and more than $90 \%$ of electricity is produced by hydropower plants, studies have been undertaken to assess vulnerability to long-term climate changes that are expected to result from increased greenhouse-gas (GHG) concentration in the atmosphere (IPCC 2001). These studies require projections of possible changes in the temporal and spatial patterns of local rainfall, temperature, and other important climatic variables.

General circulation models (GCMs) are currently the most used tool for these projections. However, due to their coarse resolution, typically $300 \mathrm{~km} \times 300 \mathrm{~km}$ in 
the tropics, they cannot be used for projecting localscale changes (Grotch \& MacCracken 1991). This is particularly true for surface climate variables needed for impact studies (Kamga 2000). Improving their resolution may by hindered due to limitations in computing power and in the understanding of all the processes involved. Furthermore, it is estimated that the skillful scale of GCMs is about 8 times the grid scale; therefore GCM output should not be applied to smaller scales (von Storch et al. 1993, Johannesson et al. 1995). Present GCM climate projections must be converted or downscaled to higher regional or local resolutions. The leading techniques used are dynamical and statistical (empirical) downscaling (Hewitson \& Crane 1996).

In dynamical downscaling, a limited-area model (LAM) of the area of interest is nested in a GCM and evolves with it while using its output as boundary conditions (Giorgi 1990, Giorgi et al. 1994). Because of their process-based approach, LAMs are expected to generate reliable regional results, since topography, land-use patterns and other geographical features can be taken into account. In spite of their resolution being about 10 times higher than that of GCMs, in some experiments; they have failed to reproduce observed precipitation statistics at the spatial and temporal scales required for regional impact assessment (Bates et al. 1998, Giorgi 1991). Furthermore, they are computationally expensive, and most impact assessment research groups do not have access to a LAM or its output.

Another strategy to overcome the gap between large and local scales is the use of empirical downscaling techniques (von Storch et al. 1993). It requires empirical linkages between large-scale circulation patterns or variables that are well resolved and projected by GCMs, and the local climate variables of interest. A model representing the relationship between largeand local-scale variables is built and calibrated with observations from the current climate, and it is assumed in most cases that these relations will still hold under a changed climate. Various methods are used, including regression analysis (Matulla et al. 2002), canonical correlation analysis (von Storch et al. 1993, Zorita et al. 1995) and neural networks (Olsson et al. 2001). Empirical methods offer an attractive approach at significantly lower computing costs (Hewitson \& Crane 1996) to assess the potential impacts of climate change in the central African region where there is no LAM running at present. However, the literature contains only a few examples of such studies in tropical Africa (e.g. Jenkins 1997, Cook 1997, Indeje et al. 2001).

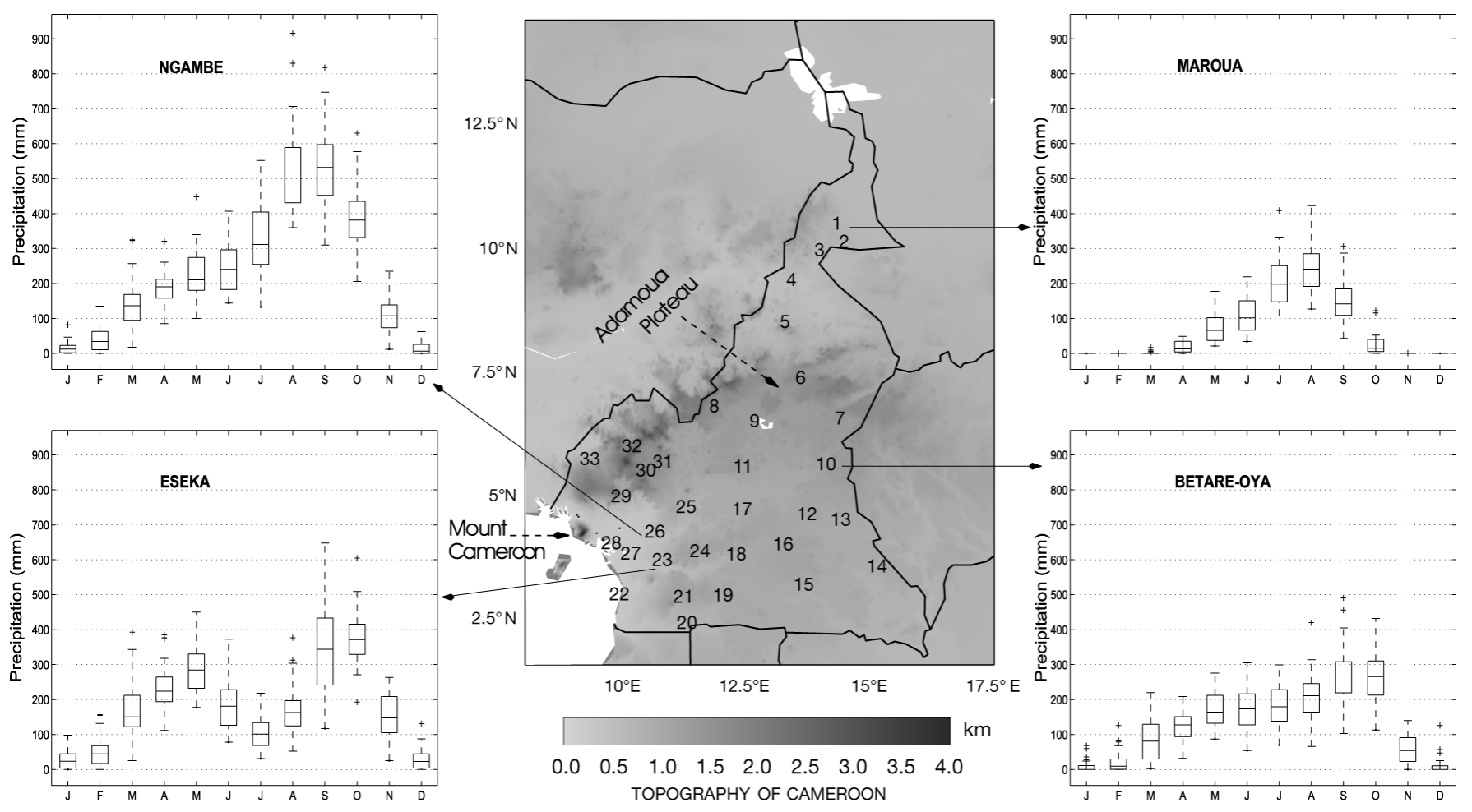

Fig. 1. Topography of Cameroon and stations used in this study. Boxplots of monthly rainfall typical of various annual rainfall regimes across the country are shown 
In this study, we are interested in local patterns of rainfall under a changed climate for Cameroon. Owing to its latitudinal extension, its proximity to the Atlantic Ocean and the variety of its relief, Cameroon has many climatic zones. In particular, the spatial rainfall patterns are quite complex (Fig. 1). Furthermore, the annual cycle of rainfall is modulated by the south-north and north-south annual migration of the Intertropical Convergence Zone (ITCZ), which marks the limit between the dry Sahelian Harmattan winds and the humid South Westerly Monsoon flow (Janowiak 1988).

The different sources of variability resulting in this spatio-temporal diversity point to the difficulties in easily identifying single large-scale variables that influence precipitation over Cameroon. Some regionalisation studies on a monthly basis have previously been done in the area (Mkankam et al. 1994) in order to characterise the sources of variability. Hence, we decided to regionalise the precipitation data before downscaling, as this strategy can be beneficial in such a situation (Woth 2001).

\section{DATA}

For model fitting of relations between large and local scales, we used monthly mean values of relative and specific humidity, temperature, geopotential height, zonal and meridional wind, vorticity and divergence at 4 pressure levels $(200,500,700$ and $850 \mathrm{hPa}$ ). Sea-level pressure and sea-surface temperature were also examined. The present climate is represented by the output of the NCEP/NCAR $50 \mathrm{yr}$ Reanalysis Project, which uses a state-of-the-art analysis/forecast system to perform data assimilation using data from 1948-1998 (Kalnay et al. 1996, Kistler et al. 2001). As only the above-mentioned large-scale predictors are used, the fact that the NCEP/NCAR Reanalysis precipitation data are not fully reliable over a part of tropical Africa north of the equator prior to 1967-1968 (Poccard et al. 2000) does not affect our downscaling approach. The data assimilation and the global spectral model are identical to the global system implemented operationally at NCEP on January 1995, except that the horizontal resolution is T62, about $210 \mathrm{~km}$. The data used, gridded in $2.5^{\circ}$ longitude $\times 2.5^{\circ}$ latitude cells, cover 1951-1990 and a sector from $20^{\circ} \mathrm{W}$ to $20^{\circ} \mathrm{E}$ and $20^{\circ} \mathrm{S}$ to $15^{\circ} \mathrm{N}$. They were downloaded from the NOAA-CIRES Climate Diagnostics Centre Website (www.cdc.noaa.gov/). The predictor domain is shifted to the south-west sector (see Figs. 3 or 4), since Cameroon precipitation climate is mainly affected by air masses originating over the Atlantic Ocean (Suchel 1987, Nicholson 2000).
At the local scale, we use 2 different monthly precipitation datasets: one obtained directly from the National Meteorological Service of Cameroon (NMSC), and the other from the Food and Agriculture Organisation (FAO) of the United Nations. Using both fragmentary sets, it was possible to extract 33 station records, with sufficient data for 1951-1990, with at most $2 \%$ missing data (Table 1, Fig. 1). In this study, we are interested in rainfall totals for the March-June (MAMJ) period, locally known as the little rainy season.

The behaviour of large-scale variables under climate change is simulated by the Max Planck Institute (MPI) coupled atmosphere-ocean GCM model ECHAM4/ OPYC3 (Roeckner et al. 1996). Kamga (2000) found that this model gives a good representation of the climate (temperature and rainfall) over Cameroon and some of its neighbouring areas and that the spatial correlations between the mean field of the NCEP/NCAR Reanalysis and the ECHAM4/OPYC3 control run patterns are larger than 0.9 .

Table 1. List of the stations used and their geographical co-ordinates. See also Fig. 1 for spatial locations

\begin{tabular}{|c|c|c|c|c|}
\hline Label & Station name & $\begin{array}{c}\text { Longitude } \\
\left({ }^{\circ}\right)\end{array}$ & $\begin{array}{l}\text { Latitude } \\
\left({ }^{\circ}\right)\end{array}$ & $\begin{array}{l}\text { Altitude } \\
\text { (m) }\end{array}$ \\
\hline 1 & Maroua & 14.25 & 10.45 & 423 \\
\hline 2 & Kaele & 14.43 & 10.08 & 338 \\
\hline 3 & Guider & 13.95 & 9.93 & 356 \\
\hline 4 & Garoua & 13.38 & 9.33 & 213 \\
\hline 5 & Poli & 13.23 & 8.48 & 436 \\
\hline 6 & Ngaoundere & 13.56 & 7.35 & 1113 \\
\hline 7 & Meiganga & 14.33 & 7.16 & 1027 \\
\hline 8 & Banyo & 11.81 & 6.75 & 1110 \\
\hline 9 & Tibati & 12.62 & 6.47 & 874 \\
\hline 10 & Betare-Oya & 14.08 & 5.6 & 805 \\
\hline 11 & Yoko & 12.36 & 5.55 & 1031 \\
\hline 12 & Bertoua & 13.73 & 4.6 & 668 \\
\hline 13 & Batouri & 14.36 & 4.46 & 655 \\
\hline 14 & Yokadouma & 15.1 & 3.52 & 640 \\
\hline 15 & Lomie & 13.61 & 3.16 & 640 \\
\hline 16 & Abong-Mbang & 13.2 & 3.96 & 693 \\
\hline 17 & Nanga-Eboko & 12.37 & 4.65 & 624 \\
\hline 18 & Akonolinga & 12.25 & 3.77 & 671 \\
\hline 19 & Sangmelima & 11.98 & 2.93 & 713 \\
\hline 20 & Ambam & 11.23 & 2.38 & 602 \\
\hline 21 & Ebolowa & 11.17 & 2.9 & 603 \\
\hline 22 & Kribi & 9.9 & 2.93 & 13 \\
\hline 23 & Eseka & 10.73 & 3.62 & 228 \\
\hline 24 & Yaounde & 11.51 & 3.83 & 760 \\
\hline 25 & Bafia & 11.16 & 4.73 & 501 \\
\hline 26 & Ngambe & 10.6 & 4.2 & 650 \\
\hline 27 & Edea & 10.13 & 3.8 & 32 \\
\hline 28 & Douala-Obs. & 9.7 & 4.01 & 10 \\
\hline 29 & Nkongsamba & 9.93 & 4.95 & 816 \\
\hline 30 & Bafoussam & 10.43 & 5.48 & 1460 \\
\hline 31 & Koundja & 10.75 & 5.65 & 1217 \\
\hline 32 & Bamenda & 10.18 & 5.93 & 1608 \\
\hline 33 & Manfe & 9.3 & 5.75 & 126 \\
\hline
\end{tabular}


In the ECHAM4 experiment, performed in 1995, the horizontal resolution of the atmospheric model was $5.6^{\circ}$ latitude $\times 5.6^{\circ}$ longitude and the ocean model was $2.8^{\circ} \times 2.8^{\circ}$. Following an initialisation period of historical GHG forcing from 1860-1990, 3 simulations were performed: (1) a 300 yr control simulation with GHG concentrations kept at 1990 levels; (2) a 'GHG only'forced experiment using a $1 \%$ annual increase in forcing for 1990-2099; and (3) a 'GHG plus sulphate aerosol' integration $\left(\mathrm{CO}_{2}+\mathrm{SO}_{4}\right.$ aerosols $)$ for 1990-2049. The $1 \%$ increase is in accordance with the IS92a emission scenario of the Intergovernmental Panel on Climate Change (IPCC 2001). The output data were interpolated to the NCEP/NCAR $2.5^{\circ} \times 2.5^{\circ}$ Reanalysis grid.

\section{REGIONALISATION OF PRECIPITATION- SELF-ORGANISING FEATURE MAP}

\subsection{The need for regionalisation}

Tropical rainfall is generated by a wide variety of mechanisms, including monsoon, coastal and upper troughs, tropical cyclones, convective and advective systems. Several studies have been carried out in various regions of Africa in order to link atmospheric variables to local rainfall. In Tanzania, Kabanda \& Jury (1999) found that for October-December rainfall is linked to wind indices in the Indian Ocean and the ENSO phase, while for March-May, only rainfall in May is linked to the all-India rainfall index (Zorita \& Tilya 2002). In West Africa, Sahelian rainfall is linked to sea-surface temperature (Thiaw et al. 1999).

In central Africa, the ITCZ is one of the phenomena affecting precipitation. In Cameroon, the Cameroon mountain chain, which extends from Mount Cameroon (altitude: $4100 \mathrm{~m}$ ) across the Adamaoua Plateau to the northwest (Cameroon's topography is displayed in Fig. 1), is another local factor that greatly affects the spatial distribution of rainfall. Moreover, Fig. 1 shows examples of precipitation regimes in the country. The wet equatorial climate with 2 rainy seasons (e.g. Eseka [Stn 23]), the dry Sahelian climate with a single rainy season (e.g. Maroua [Stn 1]) and intermediate situations (e.g. Betare-Oya [Stn 10]) are present. Note how Ngambe (Stn 26) and Eseka (Stn 23) are close (approximately $135 \mathrm{~km}$ apart), but exhibit quite different annual cycles. A small peak is observed in May in the annual rainfall cycles of most stations located southward of the country during MAMJ. During this season the rains are relatively moderate: not enough to cause floods, but sufficient to favour the sowing and the flowering of many local and commercial vegetables. Thus, perturbation of precipitation during this season has direct consequences on the population, whose activities are mainly agricultural. July-October is known as the main rainy season, with a pronounced rainfall peak observed in July, August, September or October, depending on the station.

Various mechanisms acting together or independently cause this complexity. From this point of view, it seems reasonable to group stations with similar rainfall properties before linking them to the general circulation. Thus, different atmospheric variables can be identified as sources of rainfall variability in different regions. From the range of tools available for rainfall regionalisation (e.g. cluster analysis and rotated empirical orthogonal functions [EOFs]), we used self-organising feature maps (SOFMs) because of their ability to perform classification with different statistical measurements.

SOFMs (Kohonen 1989) are a subgroup of artificial neural networks (ANNs) used to extract significant patterns or features in the input data (Haykin 1994). This methodology provides a mechanism for visualising any distribution of data on a 2-dimensional map, while preserving the statistical properties of the input distribution (Laha \& Pal 2001). SOFMs have been used in climatology for classification purposes (Malmgren \& Winter 1999, Cavazos 2000) and can achieve the same results as obtained by other methods. Hewitson \& Crane (2002) recently used SOFMs to describe changes of synoptic circulation over time, and they discussed in detail their performance and utility in climatological studies.

\subsection{Application and results of the SOFM methodology}

The architecture of SOFMs in 2 dimensions consists of 1 output layer of $m_{0} \times n_{0}$ nodes and 1 single input layer with $n$ nodes. Each node of the output layer is connected to all nodes of the input layer through the connection weights. The input data are arranged as a matrix of dimensions $m \times n$, where $m$ and $n$ are the number of observations and variables, respectively. These data are then mapped through an iterative process onto the output layer. Each iteration consists of randomly selecting an observation (input vector), finding its 'best-matching' node (the one having the smallest Euclidean distance to the input vector) and updating the connection weights not only for the best-matching node, but also for nodes in its vicinity. The updating formula is a function of the learning rate, which decreases continually during the iterations. At the end of the process, the output nodes are arranged so that observations that share similarities in the input space are mapped either through the same node or through 2 nodes close to each other in the output layer. 
Observations whose mapped nodes represent a dense area in the output layer can be interpreted as a group of data with some similar properties.

The interpretation of SOFM clusters strongly depends on the way in which the input vector is passed to the network. In the case where $m$ denotes the length of the time series and $n$ the number of grid points or stations, the similarity will be looked for in the time domain, resulting in the clusters indicating various stages of evolution through time. On the other hand, if the transposed data matrix is used, the similarity will be in the grid points or station space, leading to clusters of stations or grid points in which the time series varies in a similar way. Our data were analysed using the latter approach.

The data we used are standardised seasonal anomalies of monthly precipitation from 1951-1990 recorded at 33 stations. Application of the SOFM methodology to the data matrix leads to assigning the various stations to Regions C1, C2 and C3, as displayed in Fig. 2. Stations in Region $\mathrm{C} 1$ are located in the north and west of the domain and are characterised by a unimodal annual cycle. In view of the high variability in rainfall, as well as the altitude and latitude, the probable linkage here is the type of circulation producing precipitation. This point will become clearer later. Stations in Region C3, located in the south have a bimodal annual cycle with a clear peak of rainfall in May, when the Intertropical Front (ITF) is nearing its northernmost position, and the area is located in Zone D of the ITCZ (Hamilton \& Archibald 1945). Stations in Region $\mathrm{C} 2$ are in a transition zone between the preceding two. Note that differences in the annual cycle of rainfall at the stations in Regions $\mathrm{C} 1$ and $\mathrm{C} 3$ are a coincidence and that both unimodal and bimodal annual cycles are present in Region C2.

\section{STATISTICAL DOWNSCALING-CANONICAL CORRELATION ANALYSIS}

Statistical downscaling utilises observations in order to derive relationships between different spatial scales. These relationships can be used to obtain small-scale realisations from large-scale climate-change scenarios provided by GCMs. We use canonical correlation analysis (CCA), which attempts to find optimally coupled anomaly patterns on both spatial scales (von Storch \& Zwiers 1999). CCA has found wide application to precipitation modelling: von Storch et al. (1993) applied CCA to winter Iberian rainfall; Gyalistras et al. (1994) applied it not only to precipitation at some stations in Switzerland, but also to several other local meteorological elements; and Busuioc \& von Storch (1996) applied it to monthly Romanian precipitation amounts.

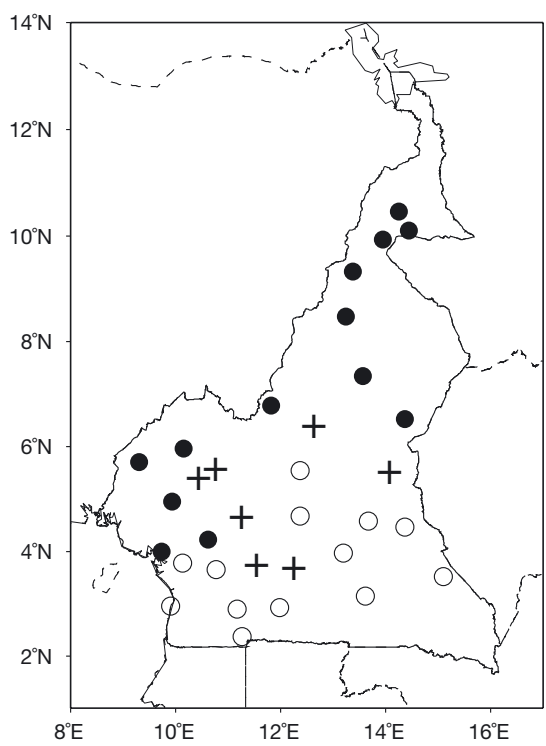

Fig. 2. Clusters found by the SOFMs methodology based on standardised rainfall anomalies for 1951-1990: (•) Region C1, (+) Region C2 and (O) Region C3

\subsection{Methodology}

The statistical downscaling model is constructed in 2 steps: First, we analyse the data on the GCM scale and the local scale using EOF analysis (Lorenz 1956, Richman 1986). The aim of this step is to discriminate between the signal of interest and the noise. This allows identification of the most important modes of variability and in some cases substantial reduction of the data dimensionality. Second, CCA is used to study the correlation structure between local precipitation and 2 large-scale meteorological variables during MAMJ in Cameroon. This step is done separately for each region found using the SOFM methodology.

\subsection{Application and results}

\subsubsection{Model building}

At the GCM and local scales, the number of EOFs retained for further analysis did not exceed 8 and was such that at least $80 \%$ of the total variance was explained. To detect atmospheric variables which have an influence on rainfall variability, all possible combinations of 2 different large-scale fields, as listed in Section 2, were used as predictors for CCA. The number of the CCA pair entering each model is equal to the dimension of the local-scale EOF spaces (i.e. 4 in the case of $\mathrm{C} 2$ and 6 in the other 2 cases).

In order to test the numerous models, 3 validation experiments, referred to as A, B and C, were con- 
Table 2. Coefficient of determination, $r^{2}$, between observed and downscaled precipitation for the little rainy season in Cameroon (MAMJ). Predictor combirelative and specific humidity; $u$ and $v$ : zonal and meridional winds; $\operatorname{div} V$ and $\operatorname{rot} V$ : wind divergence and vorticity; subscripts $8,7,5: 850,700$ and $500 \mathrm{hPa}$ pressure levels. PSR: percentage of stations with $r$ significant at $95 \%$

\begin{tabular}{|c|c|c|c|c|c|c|c|}
\hline Expt & Predictors & Region & Min. & Max. & Mean & $\mathrm{SD}$ & PSR $\geq 95 \%$ \\
\hline \multirow[t]{4}{*}{ A } & $\mathrm{RH}_{8}+\mathrm{v}_{8}$ & $\mathrm{C} 1$ & 0.23 & 0.51 & 0.39 & 0.09 & 100 \\
\hline & $\mathrm{SH}_{7}+\mathrm{u}_{5}$ & $\mathrm{C} 2$ & 0.19 & 0.35 & 0.24 & 0.07 & 71 \\
\hline & $\mathrm{SH}_{5}+\operatorname{divV} V_{7}$ & $\mathrm{C} 3$ & 0.13 & 0.45 & 0.29 & 0.09 & 100 \\
\hline & $\mathrm{SH}_{5}+\operatorname{rot} \mathrm{V}_{5}$ & ALL & 0.11 & 0.48 & 0.27 & 0.11 & 91 \\
\hline \multirow[t]{4}{*}{ B } & $\mathrm{RH}_{8}+\mathrm{v}_{8}$ & $\mathrm{C} 1$ & 0.15 & 0.49 & 0.31 & 0.11 & 100 \\
\hline & $\mathrm{SH}_{7}+\mathrm{u}_{5}$ & $\mathrm{C} 2$ & 0.14 & 0.27 & 0.20 & 0.07 & 71 \\
\hline & $\mathrm{SH}_{5}+\operatorname{div} \mathrm{V}_{7}$ & $\mathrm{C} 3$ & 0.16 & 0.50 & 0.31 & 0.11 & 100 \\
\hline & $\mathrm{SH}_{5}+\operatorname{rot} V_{5}$ & ALL & 0.10 & 0.49 & 0.27 & 0.11 & 91 \\
\hline \multirow[t]{4}{*}{$\mathrm{C}$} & $\mathrm{RH}_{8}+\mathrm{v}_{8}$ & $\mathrm{C} 1$ & 0.19 & 0.38 & 0.26 & 0.11 & 43 \\
\hline & $\mathrm{SH}_{7}+\mathrm{u}_{5}$ & $\mathrm{C} 2$ & 0.12 & 0.12 & 0.12 & 0.00 & 14 \\
\hline & $\mathrm{SH}_{5}+\operatorname{div} V_{7}$ & C3 & 0.16 & 0.16 & 0.16 & 0.00 & 8 \\
\hline & $\mathrm{SH}_{5}+\operatorname{rot} V_{5}$ & ALL & 0.20 & 0.20 & 0.20 & 0.00 & 3 \\
\hline
\end{tabular}
nation and statistics characterising the distribution of $r$ are shown. $\mathrm{RH}$ and $\mathrm{SH}$ :

southerly wind at the $850 \mathrm{hPa}$ level located around $5^{\circ} \mathrm{N}$ westwards of Cameroon. The meridional wind intensity increases northwards up to $5^{\circ} \mathrm{N}$, then quickly decreases and is reversed around $13^{\circ} \mathrm{N}$. The area of positive relative humidity can be interpreted as the persistent presence of humid air masses advected from the Atlantic Ocean. Hence, deep convection producing precipitation in Region $\mathrm{C} 1$ results from moisture advection by the monsoonal flow.

This possible connection was further explored by means of a composite analysis involving local precipitation, large-scale relative humidity and meridional wind. The upper 2 panels in Fig. 4a show the result of the analysis. COMPOSITE+ is for the largescale composites made up of years structed. In Expt A the (EOF-CCA) model is calibrated and validated for 1951-1990. In Expt B the model is calibrated using 1951-1980 and validated over the whole period, and in Expt $C$, the calibration and the validation periods are 1951-1970 and 1971-1990, respectively. These choices are guided by the short length $(40 \mathrm{yr})$ of the time series. The experiments are carried out separately for each of the homogeneous regions found by the SOFM methodology (see Fig. 2) and for the region as a whole (denoted ALL). To assess the performance of the various models, we calculate the Pearson correlation coefficient, $r$, between the estimated and observed time series and test its significance at the $95 \%$ significance level. The best-performing models are selected to downscale the GCM scenarios.

The skill of a particular predictor combination is measured by means of the coefficient of determination, $r^{2}$, and the percentage of stations with significant $r$. In the following discussion the percentage of stations with a significant $r$ will be abbreviated as PSR. Table 2 displays the predictors, results obtained from the previously described selection process, and their $r^{2}$ statistics for MAMJ.

\subsubsection{Results and discussion}

Fig. 3 shows the first CCA patterns for each rainfall region. The CCA rainfall pattern in Region C1 explains $37 \%$ of total variance. For comparison, the first rainfall EOF for Region C1 (not shown) explains $43 \%$ of total variance. At a large scale (Fig. 3a), the area is under the strong influence of positive relative humidity and having exceptionally high precipitation totals at the stations in Region C1 during MAMJ. COMPOSITEcorresponds to the opposite situation, i.e. years having considerably lower precipitation totals during MAMJ. The composite analysis supports the interpretation above, as the composites related to high precipitation are similar to those related to low precipitation but with a reversed sign.

In Region C3 the composite analysis also supports the CCA results. The CCA (Fig. 3c) and COMPOSITE patterns of specific humidity at $500 \mathrm{hPa}$ and the wind divergence at $700 \mathrm{hPa}$ (Fig. 4b) show many similarities. In COMPOSITE+ there is wind convergence around $5^{\circ} \mathrm{N}$ and relative humidity is positive over Cameroon. This combination feeds convection and can explain the enhanced precipitation recorded at the stations in Region C3. The COMPOSITE-, which is connected to drier episodes, shows positive divergence around the region of interest. Taken together, these observations point to convective phenomena as the key source of rain in this area.

The CCA patterns of specific humidity at $700 \mathrm{hPa}$ and zonal wind at $500 \mathrm{hPa}$ (Fig. 3b) show a complex situation in the case of stations in Region C2 with a south-north dipole for zonal wind and an east-west dipole for specific humidity around the Equator. These patterns do not allow a simple interpretation, and no further investigation has been made using composites. Furthermore, the results presented in Table 2 indicate that rainfall in Region C2 is more weakly related to large-scale circulation than in the other 2 regions. In all cases, it can be observed that precipitation during MAMJ is related to the state of the atmosphere below the $500 \mathrm{hPa}$ level and around $5^{\circ} \mathrm{N}$. 
The CCA models as calibrated in Expt A were used to downscale rainfall under the present climate. Fig. 5 shows a direct comparison between observed and downscaled rainfall anomalies for each region. It appears that the CCA models capture the interannual variability of precipitation in Regions $\mathrm{C} 1$ and $\mathrm{C} 3$ reasonably well, although extreme values, particularly in Region $\mathrm{C} 3$, are underestimated. The trends are well reproduced in both Regions $\mathrm{C} 1$ and $\mathrm{C} 3$, although it has to be remembered that the Expt A models were fitted
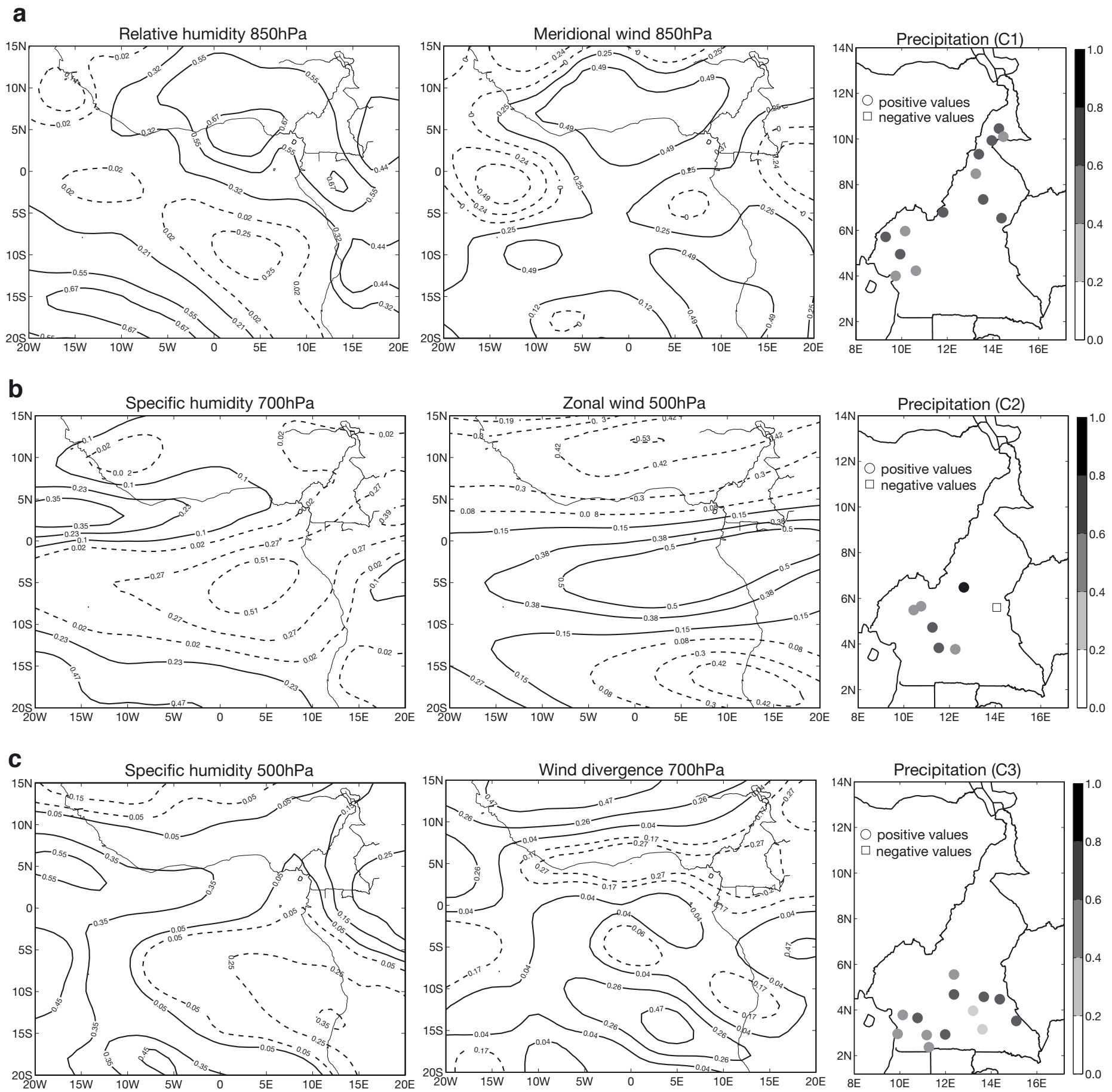

Fig. 3. First CCA patterns associated with MAMJ rainfall for the SOFM-defined homogeneous regions. Values are standardised. Canonical correlations between first time coefficients are 0.88 for Region C1 (a), 0.73 for Region C2 (b) and 0.76 for Region C3 (c) 
a
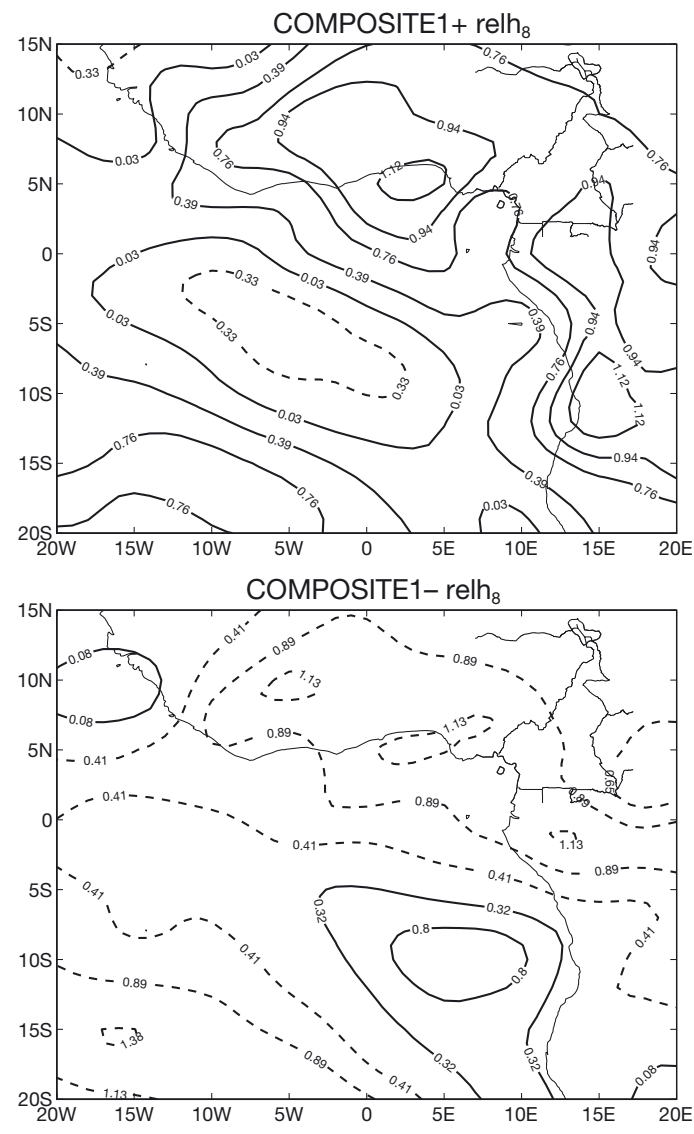

b
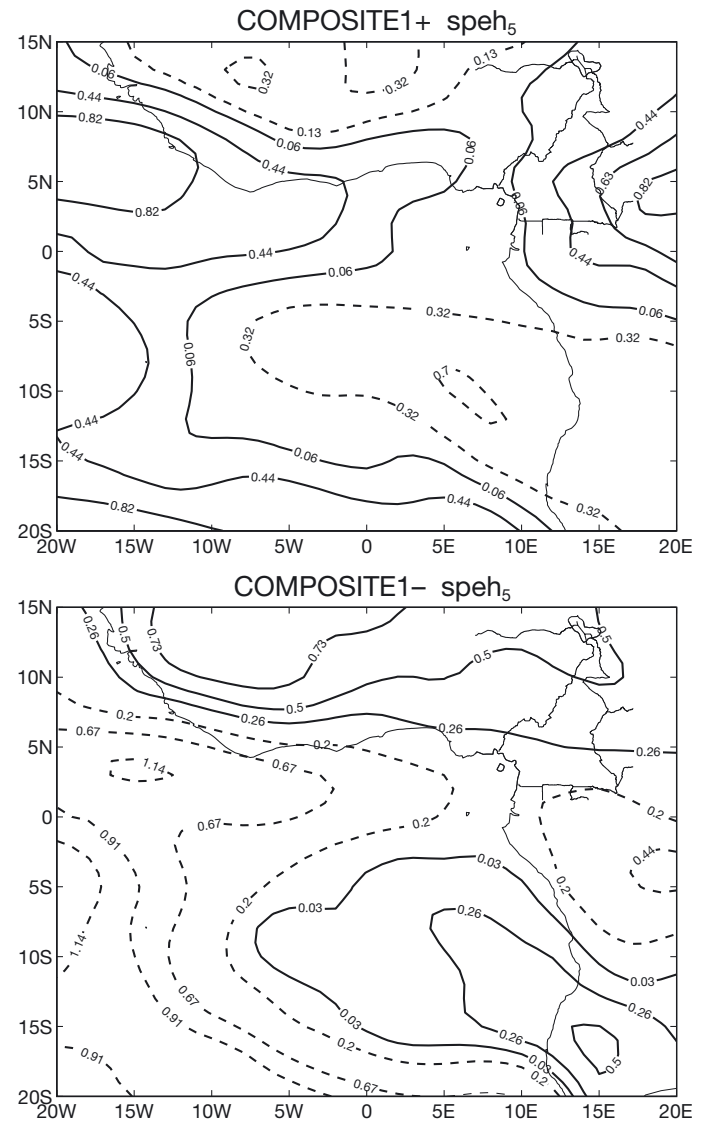
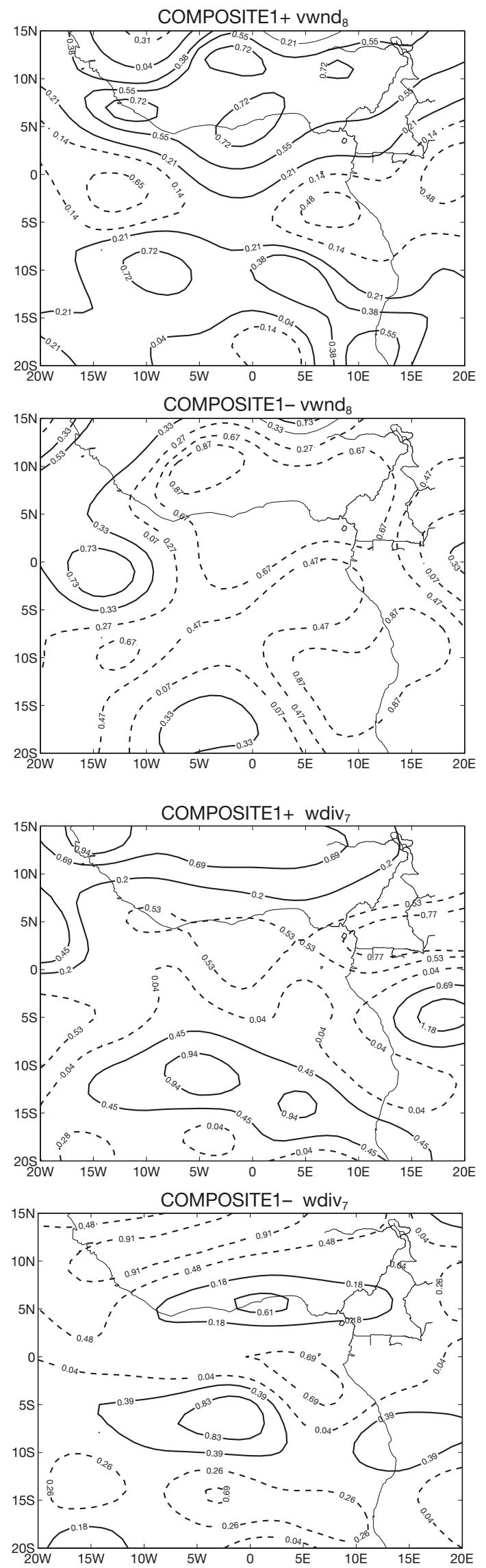

Fig. 4. Composite patterns of predictor variables for (a) Region C1 and (b) Region C3. COMPOSITE+ (COMPOSITE-) is the mean state made up of the 6 highest (lowest) values of the canonical time series. Values are standardised 

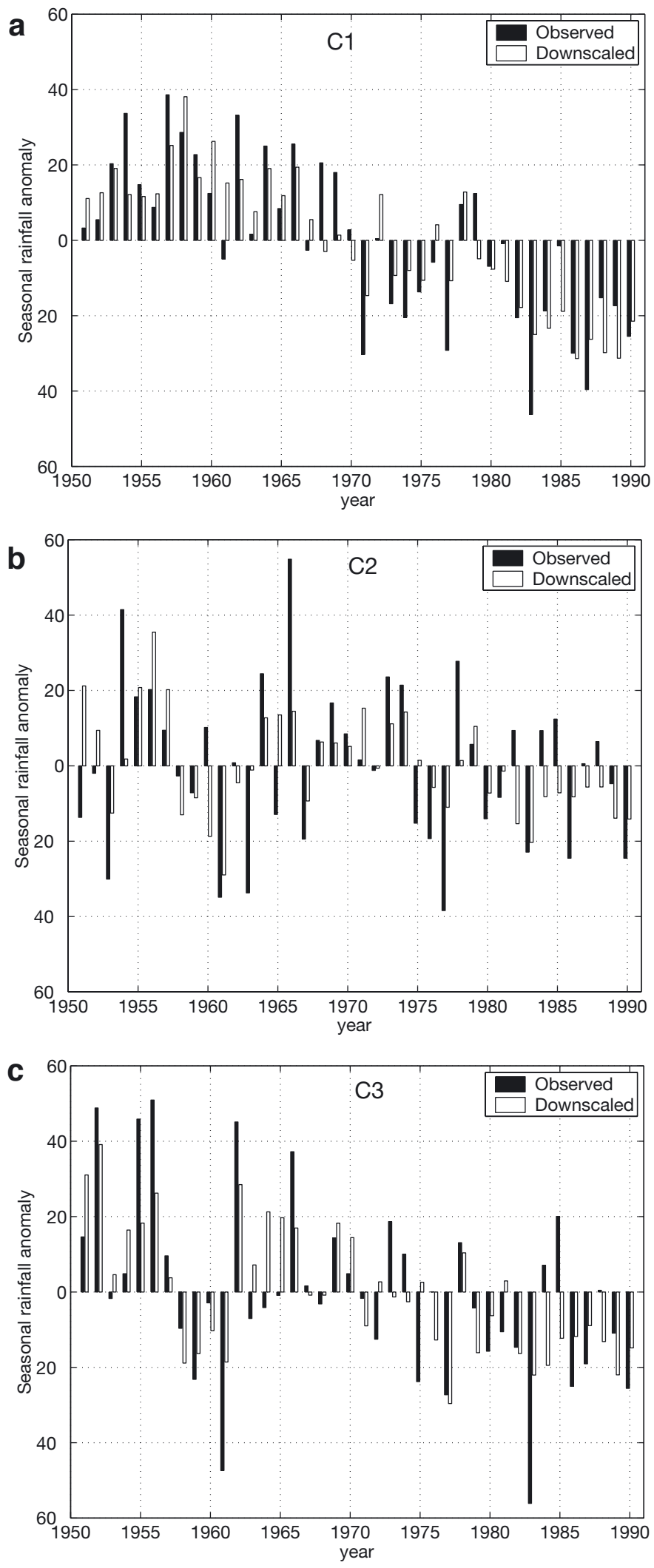

Fig. 5. Time series of MAMJ rainfall averaged over the homogeneous regions (a) C1, (b) $\mathrm{C} 2$ and (c) C3. Black bars: observed; white bars: estimated from Expt A
Table 3. Model performance with regionalisation $\mathrm{C} 1, \mathrm{C} 2$, and C3 and without (ALL). Values are $\overline{r^{2}} \leftrightarrow($ PSR $=95 \%$ ) (see text)

\begin{tabular}{|lccccccc|}
\hline Expt & C1 & $\begin{array}{c}\text { C1 in } \\
\text { ALL }\end{array}$ & C2 & $\begin{array}{c}\text { C2 in } \\
\text { ALL }\end{array}$ & C3 & $\begin{array}{c}\text { C3 in } \\
\text { ALL }\end{array}$ & ALL \\
\hline A & 0.39 & 0.24 & 0.17 & 0.16 & 0.29 & 0.25 & 0.25 \\
B & 0.31 & 0.23 & 0.14 & 0.13 & 0.31 & 0.27 & 0.25 \\
C & 0.11 & 0.00 & 0.02 & 0.03 & 0.01 & 0.00 & 0.01 \\
\hline
\end{tabular}

over the entire validation period. Again, it can be seen that there are difficulties in Region $\mathrm{C} 2$, where the results are weakly matched to observation. These difficulties may be associated with local-scale processes, which are poorly resolved by the GCMs (Soon et al. 2001).

When the models are calibrated and validated over independent periods (Expt C), there are only 5 stations with significant correlations in the case of downscaling after regionalisation (Table 2). However, in the case of using one model for Cameroon, only 1 station shows a significant correlation. This poor result of Expt $\mathrm{C}$ is related to the failure to reproduce the low-frequency variability in the observations, i.e. the relative wetness of 1951-1970 compared with the drier 1971-1990, particularly evident in Regions C1 and C3 (see Fig. 5a,c).

When the models are calibrated and validated over the same, non-independent, $20 \mathrm{yr}$ period, i.e. 1951-1970 and 1971-1990, performance for both periods (not shown) is almost the same as for Expt A. This again indicates that model skill is related to the presence of low-frequency variability.

To assess the benefit of regionalising precipitation data using SOFM analysis before downscaling, we weight the mean performance (achieved by the predictor combinations actually used) with the percentage of stations with significant correlation at the $95 \%$ level [i.e. $\left.\overline{r^{2}} \times(\mathrm{PSR} \geq 95 \%)\right]$. The results are shown in Table 3. In this table, Region C1 (C2, C3) in ALL means that the statistics are calculated for the stations in Region $\mathrm{C} 1(\mathrm{C} 2, \mathrm{C} 3)$ with the results of the model run for ALL. It appears that regionalisation of rainfall data improves model performance in Regions $\mathrm{C} 1$ and $\mathrm{C} 3$, but is of little help in Region C2. Although the model performance is better in ALL than in Region C2, comparing the performance region by region shows that local precipitation is better represented when running the model separately for each region.

\subsubsection{Downscaled local rainfall under climate change}

The transfer functions derived from the EOF-CCA approach (Section 4.2.2) are used to assess local precipitation changes for a future period. The GCM used 
is ECHAM4/OPYC3 (Roeckner et al. 1996) as described earlier. Two IS92a scenarios are investigated; the 'GHG only' run for 2011-2050 and the 'GHG plus sulphate aerosols' run for 2010-2049. The predictor anomalies are derived by subtracting climatological mean values, 1951-1990, calculated from the control experiment, from the values calculated from the scenario runs. The predictor anomalies are further normalised by the NCEP/ NCAR Reanalysis data standard deviation for 1951-1990. The models used were calibrated with the set-up described in Expt A. Table 4 shows the percentage difference between the climatological values for the control period 1951-1990 and the projected values for 2011-2050 ( $\mathrm{CO}_{2}$ only) as well as 2010-2049 $\left(\mathrm{CO}_{2}+\mathrm{SO}_{4}\right)$.

The statistics describe each region separately. Fig. 6 shows the spatial distribution of precipitation changes induced by the $\mathrm{CO}_{2}$ only and $\mathrm{CO}_{2}+\mathrm{SO}_{4}$ scenarios. The changes are expressed as percentages relative to the control period 1951-1990. The largest changes appear in Region C1 (up to $44 \%$ increase). This may be due to a slight movement towards the east of the positive centre (Fig. 3) around $5^{\circ} \mathrm{N}$, north of the relative humidity and the meridional wind at $850 \mathrm{hPa}$. The rest of the country (i.e. the Regions C2 and C3) shows both positive (increase) and negative (decrease) precipitation changes ranging from -10 to $+10 \%$. The results induced by the $\mathrm{CO}_{2}+\mathrm{SO}_{4}$ scenario look quite similar to those of the $\mathrm{CO}_{2}$-only scenario with differences in magnitude up to $\pm 8 \%$.

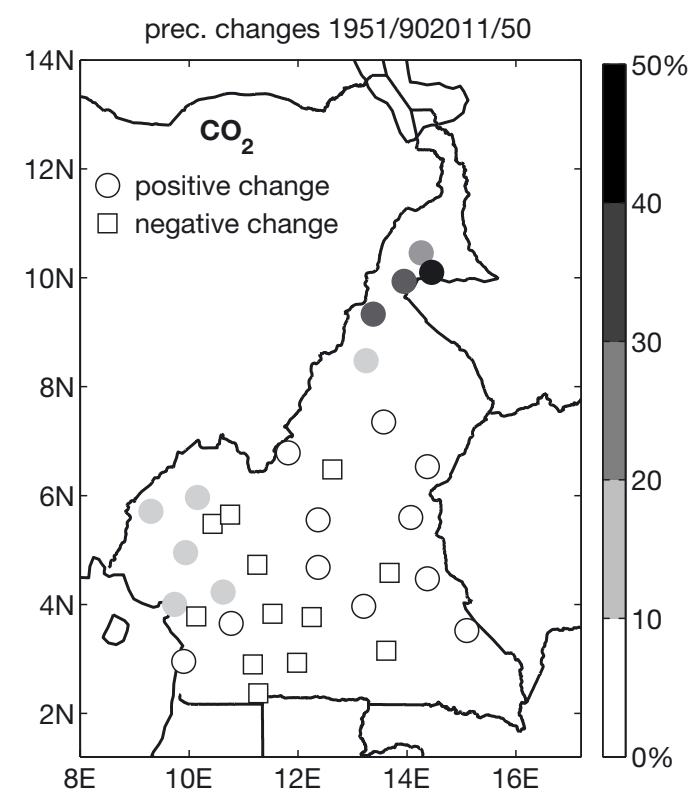

Table 4. Statistics of downscaled local rainfall changes derived from a GCM experiment under the IPCC IS92a scenario with $\mathrm{CO}_{2}$ only and $\mathrm{CO}_{2}+\mathrm{SO}_{4}$. Changes are expressed as percentages relative to the control period 1951-1990

\begin{tabular}{|lrrrrrrrr|}
\hline \multirow{2}{*}{ Region } & \multicolumn{4}{c}{$\mathrm{CO}_{2}$ only } & \multicolumn{4}{c|}{$\mathrm{CO}_{2}+\mathrm{SO}_{4}$} \\
& Min. & Max. Mean & \multicolumn{2}{c|}{$\mathrm{SD}$} & Min. & Max. Mean & SD \\
\hline C1 & 4 & 43.91 & 18.6 & 11.97 & 3.32 & 35.04 & 14.37 & 9.29 \\
$\mathrm{C} 2$ & -9.84 & 1.22 & -3.99 & 3.49 & -8.24 & 0.89 & -3.38 & 2.82 \\
$\mathrm{C} 3$ & -1.58 & 0.78 & -0.09 & 0.63 & -1.26 & 1.48 & 0.43 & 0.68 \\
& & & & & & & & \\
\hline
\end{tabular}

To compare these changes to the uncertainty introduced by the downscaling model, we selected in each rainfall group the station that shows the most pronounced change. The stations are Kaele, Betare-Oya and Nanga-Eboko for Regions C1, C2 and C3 respectively. Fig. 7 shows boxplots of observed, validated (Expt A) and downscaled rainfall at the stations. The variability of rainfall derived from the validation model is always within the observed variability. This remains true in the case of the downscaled scenarios.

The projected enhancement of precipitation in Region C1 could induce positive repercussions on the monthly discharge of the Upper Benue River in the north of Cameroon, with direct impacts on agricultural and human activities (Kamga 2001). Overall, most of these changes lie within the observed variability. The northernmost region that was hit by drought events during the last 20 yr (see Fig. 5) shows pronounced increases of the mean MAMJ precipitation totals.

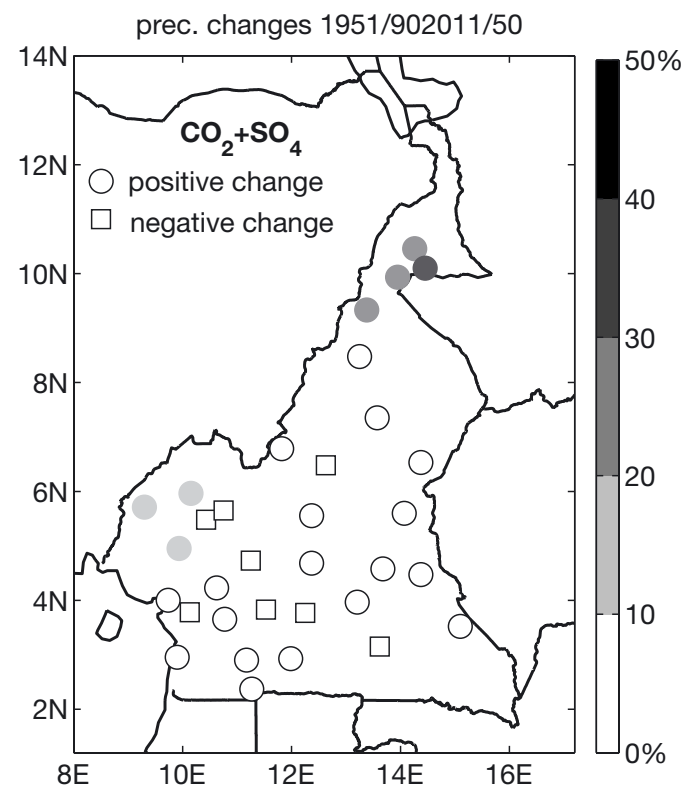

Fig. 6. Downscaled local rainfall changes derived from a GCM experiment under IPCC IS92a scenario: (a) $\mathrm{CO}_{2}$ only; (b) $\mathrm{CO}_{2}+$ $\mathrm{SO}_{4}$. Changes are expressed as percentages relative to the control period 1951-1990 


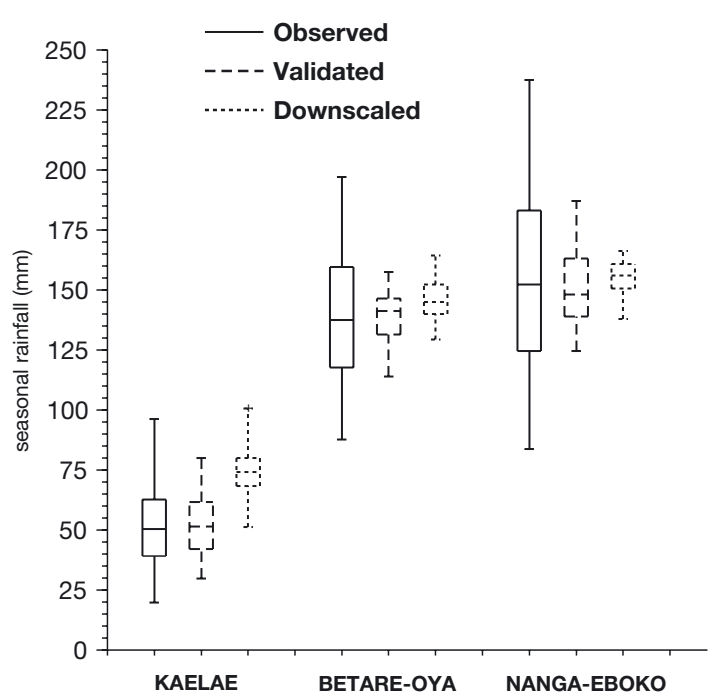

Fig. 7. Boxplot of observed, validated and downscaled rainfall for the station with the largest change in each rainfall region. Region 1: Kaele; Region 2: Betare-Oya; Region 3: NangaEboko

\section{CONCLUSIONS}

The results of a self-organising feature map (SOFM) analysis indicate that precipitation in the little rainy season (MAMJ) in Cameroon is subdivided into 3 regional groups. These groups are linked to different modes of variability, which may be related to different atmospheric mechanisms. Results of the EOF and CCA techniques show that in part of the study domain relative humidity and meridional wind at $850 \mathrm{hPa}$ influence the local precipitation during MAMJ. A composite analysis suggests that this might be due to advective processes. In the southern part of Cameroon, the combination of $500 \mathrm{hPa}$ specific humidity and $700 \mathrm{hPa}$ wind divergence provides the best link to the variability of local precipitation. In this case, the composite analysis indicates a connection between rainfall and convective phenomena. Projection of future precipitation based on 2 IS92a emission scenarios as simulated by ECHAM4/OPYC3 indicates 'trace gas only'and 'trace gas plus sulphate integration'-induced changes, relative to the 1951-1990 control period, ranging locally from +44 to $-10 \%$ and from +36 to $-9 \%$, respectively.

This study demonstrates the possibility of downscaling local-scale climate-change scenarios from GCMs for Cameroon. The approach presented offers a possible strategy to produce these scenarios at low computing cost. Cameroon's present-day climate ranges from humid-equatorial close to the Atlantic Ocean to aridtropical in the vicinity of Lake Chad, in the Sahelian zone. Hence, the results obtained may be relevant for neighbouring areas in central Africa.
Acknowledgements. We thank the German High Performance Computing Centre for Climate and Earth System Research (DKRZ), the Food and Agriculture Organization (FAO) of the United Nations and the National Meteorological Service of Cameroon (NMSC) for providing data. Moreover, we would like to thank E. Zorita, S. Wagner and C. Nunneri for fruitful discussions that helped to improve the manuscript. We also thank 3 anonymous reviewers for their suggestions. E.K.P. appreciates the German Co-operation Agency (DAAD) for granting him a fellowship and H.v.S. for welcoming him in his laboratory.

\section{LITERATURE CITED}

Bates BC, Charles SP, Hughes JP (1998) Stochastic downscaling of numerical climate model simulation. Environ Model Software 13(3-4):325-331

Busuioc A, von Storch H (1996) Changes in the winter precipitation in Romania and its relation to the large-scale circulation. Tellus 48A:538-552

Cavazos T (2000) Using self-organizing maps to investigate extreme climate events: an application to wintertime precipitation in the Balkans. J Clim 13:1718-1732

Cook KH (1997) Large-scale atmospheric dynamic and Sahelian precipitation. J Clim 10:1137-1152

Giorgi F (1990) Simulation of regional climate using a limited area model nested in a general circulation model. J Clim 3: 941-963

Giorgi F (1991) Sensitivity of simulated summertime precipitation over the Western United States to different physics parameterizations. Mon Weather Rev 119: $2870-2888$

Giorgi F, Shields Brodeur C, Bates GT (1994) Regional climate-change scenarios over the United-States produced with a nested regional climate model. J Clim 7:375-399

Grotch SL, MacCracken MC (1991) The use of general circulation models to predict regional climatic change. J Clim 4: 286-303

Gyalistras D, von Storch H, Fischlin A, Beniston M (1994) Linking GCM simulated climatic changes to ecosystem models: case studies of statistical downscaling in the Alps. Clim Res 4:167-189

Hamilton RA, Archibald JW (1945) Meteorology of Nigeria and adjacent territory. Q J R Meteorol Soc 71:231-264

Haykin S (1994) Neural networks: a comprehensive foundation. Macmillan College Publishing Company, New York

Hewitson BC, Crane RG (1996) Climate downscaling: techniques and application. Clim Res 7:85-95

Hewitson BC, Crane RG (2002) Self-organizing maps: applications to synoptic climatology. Clim Res 22:13-26

Hulme M (1992) Rainfall changes in Africa-1931-1960 to 1961-1990. Int J Climatol 7:685-699

Indeje M, Semazzi FHM, Xie L, Ogallo LJ (2001) Mechanistic model simulations of the East African climate using NCAR regional climate model: influence of large-scale orography on the Turkana low-level jet. J Clim 14: 2710-2724

IPCC (2001) Climate change 2001 - the scientific basis. Contribution of Working Group I to the Third Assessment Report of the Intergovernmental Panel on Climate Change. Cambridge University Press, Cambridge

Janowiak EJ (1988) An investigation of interannual rainfall variability in Africa. J Clim 1:240-255

Jenkins GS (1997) The 1988 and 1990 summer season simulations for West Africa using a regional climate model. J Clim 10:1255-1272 
Johannesson T, Jonsson T, Källen E, Kaas E (1995) Climate change scenarios for the Nordic countries. Clim Res 5: 181-195

Kabanda TA, Jury MR (1999) Inter-annual variability of short rains over northern Tanzania. Clim Res 13:231-241

Kalnay E, Kanamitsu M, Kistler R, Collins W, Deaven D and 17 others (1996) The NCEP/NCAR Reanalysis Project. Bull Am Meteorol Soc 77:437-471

Kamga FM (2000) Validation of general circulation climate models and projections of temperature and rainfall changes in Cameroon and some of its neighbouring areas. Theor Appl Climatol 67:97-107

Kamga FM (2001) Impact of greenhouse gas induced climate change on the runoff of the Upper Benue River (Cameroon). J Hydrol 252:145-156

Kistler R, Kalnay E, Collins W, Saha S, White G and 8 others (2001) The NCEP-NCAR 50-Year Reanalysis: monthly mean CD-ROM and documentation. Bull Am Meteorol Soc 82:247-267

Kohonen T (1989) Self-organization and associative memory, 3rd edn. Springer-Verlag, Berlin

Laha A, Pal NR (2001) Dynamic generation of prototypes with self-organizing feature maps for classifier design. Pattern Recognition 34:315-321

Lorenz EN (1956) Empirical orthogonal functions and statistic weather prediction. Sci Rept No. 1, Statistical Forecasting Project, Dept of Meteorology, Massachusetts Institute of Technology, Cambridge

Malmgren BA, Winter A (1999) Climate zonation in Puerto Rico based on principal components analysis and an artificial neural network. J Clim 12:977-985

Matulla C, Groll N, Kromp-Kolb H, Scheifinger H, Lexer MJ, Widmann M (2002) Climate change scenarios at Austrian National Forest Inventory sites. Clim Res 22:161-173

Mkankam KF, Tsalefac M, Mbane BC (1994) Variabilité pluviometrique sur le territoire Camerounais: essai de regionalisation a partir des cumuls mensuels et du cycle annuel. Publ Assoc Int Climatol 7:439-446

Nicholson SE (1993) An overview of African rainfall fluctuation of the last decade. J Clim 6:1463-1466

Nicholson SE (2000) The nature of rainfall variability over

Editorial responsibility: Clare Goodess,

Norwich, UK
Africa on time scales of decades to millenia. Global Planet Change 26:137-158

Olsson J, Uvo CB, Jinno K (2001) Statistical atmospheric downscaling of short-term extreme rainfall by neural networks. Phys Chem Earth B 26:695-700

Poccard I, Janicot S, Camberlin P (2000) Comparison of rainfall structures between NCEP/NCAR reanalyses and observed data over tropical Africa. Clim Dyn 16:897-915

Richman MB (1986) Rotation of principal components. Int J Climatol 6:293-335

Roeckner E, Oberhuber J, Bacher A, Christoph M, Kirchner I (1996) ENSO variability and atmospheric response in a global coupled atmosphere-ocean GCM. Clim Dyn 12: $737-745$

Soon W, Baliunas S, Idso SB, Kondratyev KYa, Posmentier ES (2001) Modelling climatic effects of anthropogenic carbon dioxide emissions: unknowns and uncertainties. Clim Res 18:259-275

Suchel JB (1987) Les climats du Cameroun. Thèse de Doctorat (Référence: 87BOR30044), Université de Bordeaux 3

Thiaw WM, Barnston GA, Kumar V (1999) Predictions of African rainfall on the seasonal timescale. J Geophys Res 104:31589-31597

von Storch H, Zwiers F (1999) Statistical analysis in climate research. Cambridge University Press, Cambridge

von Storch H, Zorita E, Cubasch U (1993) Downscaling of global climate change estimates to regional scales: an application to Iberian rainfall in wintertime. J Clim 6: 11161-11171

Woth K (2001) Abschätzung einer zukünftigen Niederschlagsentwicklung mit statistischen Methoden unter Einbezug räumlicher Differenzierungsverfahren am Beispiel des südwesteuropäischen Raums. Master's thesis, GKSSReport 2001/28, University of Trier

Zorita E, Tilya FF (2002) Rainfall variability in Northern Tanzania in the March-May season (long rains) and its links to large-scale climate forcing. Clim Res 20:31-40

Zorita E, Hughes JP, Lettemaier DP, von Storch H (1995) Stochastic characterization of regional circulation patterns for climate model diagnosis and estimation of local precipitation. J Clim 8:1023-1042

Submitted: March 7, 2003; Accepted: March 10, 2004

Proofs received from author(s): April 23, 2004 